\title{
PROGRAMAÇÃO LINEAR APLICADA À PROBLEMAS DE DESIGNAÇÃO DE MÃO DE OBRA BASEADA NAS COMPETÊNCIAS PROFISSIONAIS
}

\author{
Braz Dias de Andrade Júnior \\ Fundação Comunitária de Ensino Superior de Itabira - FUNCESI \\ brazj1989@hotmail.com \\ Thais Cotta Barbosa Reis \\ Fundação Comunitária de Ensino Superior de Itabira - FUNCESI \\ thais_cotta@yahoo.com.br \\ Fabricio Roulin Bittencout \\ Fundação Comunitária de Ensino Superior de Itabira - FUNCESI \\ fabriciorb@gmail.com \\ Patricia Carla Brito Neves \\ Fundação Comunitária de Ensino Superior de Itabira - FUNCESI \\ patriciacb.neves@gmail.com \\ Jackson de Assis Reis \\ Faculdade Pitágoras \\ jackson.assisreis@gmail.com
}

\begin{abstract}
Resumo
Este trabalho objetiva analisar como um modelo de programação linear da PO pode ser utilizado para alocar profissionais em uma escola de formação profissionalizante com base em suas competências. Para se atingir o objetivo desta pesquisa desenvolveu-se um modelo com função objetivo de maximizar as competências alocadas, observando os parâmetros classificação de competências de instrutores e ocorrência de disciplinas simultâneas, além das restrições de se alocar um instrutor para cada disciplina e nunca o mesmo instrutor em disciplinas simultâneas. Foram observados melhores indicadores do modelo em relação a alocação manual, ou seja, maior numero de disciplinas com instrutores mais competentes alocados. As entrevistas foram utilizadas para identificar vantagens e desvantagens do modelo. Os entrevistados destacaram a melhor utilização do tempo por parte dos gestores que realizam a alocação dos docentes em disciplinas e também dos docentes designados. Alegaram também que a otimização das competências alocadas gera melhoria nas aulas, e na qualidade do aluno de seus cursos. Como desvantagem do modelo foi destacada uma maior flexibilidade do método manual. O estudo concluiu que se pode aplicar um modelo de PL à alocação de mão de obra baseada em competências na referida escola como ferramenta que auxilie a tomada de decisão dos gestores.

Palavras-Chaves: Alocação de profissionais. Competência; Designação; Gestão por Competências; Pesquisa operacional; Problemas de designação; Programação inteira binária; Programação linear.
\end{abstract}




\section{INTRODUÇÃO}

A competitividade do mercado aumenta a cada dia e para buscar manter-se neste mercado e crescer, as empresas devem possuir um capital humano capaz de enfrentar desafios. Além de contratar pessoas qualificadas é necessário aproveitar ao máximo o potencial das pessoas. Gerenciar pessoas dando oportunidade de se desenvolverem nas áreas onde suas competências são necessárias é uma atividade complexa, mas essencial para que as organizações se desenvolvam. O modelo de administração que utiliza esta ferramenta é a gestão por competências.

Muitas empresas utilizam a estratégia de aproximar seus colaboradores das áreas e projetos para os quais possuam competências. Quando o número de funcionários e de projetos aumenta a tarefa de se decidir quem trabalhará em cada área se torna complexa. Se esta análise e alocação é realizada manualmente o trabalho pode se tornar demorado e não atingir os melhores resultados devido a falhas humanas.

A Pesquisa Operacional (PO) é um ramo das ciências que pode fornecer ferramentas a diversas áreas, incluindo a gestão de pessoas. Uma das tratativas da PO é o problema de designação que pode ser aplicado a este contexto na busca de alocar profissionais em atividade ligadas à suas competências. De forma a aproximar as pessoas de suas áreas de afinidade, gerando a melhor designação possível, observando as possíveis restrições rapidamente por meio de sistemas automáticos.

Este trabalho objetiva apresentar uma possível solução de PO, aplicada a problemas de alocação de instrutores de formação profissional em disciplinas de cursos profissionalizantes, com base nas competências destes profissionais. Devendo ainda descrever um modelo de programação linear utilizado para este fim, assim como analisar as implicações, vantagens e desvantagens deste modelo, em relação ao processo manual de alocação de mão de obra.

Para tanto este trabalho está dividido em cinco tópicos. A introdução no primeiro tópico. Um breve referencial teórico que embasa cientificamente este trabalho é apresentado no tópico dois. No tópico três estão relacionadas às metodologias de pesquisa utilizadas. Nos tópicos quatro e cinco estão, respectivamente, a análise de dados e conclusões.

\section{REFERENCIAL TEÓRICO}

Este tópico apresenta um breve estudo teórico para embasar esta pesquisa relacionando a Pesquisa Operacional com a gestão por competências.

Para garantir o sucesso do futuro as empresas precisam potencializar seu capital humano hoje. Para isto é necessário algumas medidas como a identificar o capital humano por meio de um banco de talentos com o mapeamento das competências de cada funcionário, potencializar as competências de seus funcionários aprimorando o sistema de identificação e alocação de talentos, ou seja, fazer com que o colaborador exerça a atividade mais adequada à sua base de competência, e promover o compartilhamento das competências valorizando os profissionais que traçam experiências e conhecimentos [1].

A gestão por competências é um modelo de administração de pessoas baseada nos conhecimentos, habilidades e atitudes das pessoas. Constitui-se de um conjunto de ferramentas que promovem um aperfeiçoamento contínuo dos conhecimentos. Deve-se avaliar as competências necessárias, não só às pessoas, mas à organização como um todo. Após esta avaliação é realizado o mapeamento das competências para identificar a distância entre as competências necessárias e aquelas que as organizações já possuem. A certificação de competências é a fase na qual se avalia o domínio de competências pelas pessoas. Completando o ciclo deve-se estabelecer práticas que minimizem a divergência entre as competências necessárias e as existentes [1]. 
Gerir pessoas baseando-se em suas competências é uma maneira de atingir os objetivos das empresas, valorizando o conhecimento destas pessoas, mas possui desafios relacionados ao julgamento e à escolha das ações. Neste contexto, a PO tem relevante importância, pois busca soluções, considerando as restrições e o objetivo a ser alcançado.

A Pesquisa Operacional consiste no desenvolvimento de métodos científicos de sistemas complexos, com a finalidade de prever e comparar estratégias ou decisões alternativas. O objetivo é dar suporte à definição de políticas e determinação de ações de forma científica. Para alguns autores, pesquisa operacional significa abordagem científica para tomada de decisões, que procura determinar como melhor projetar e operar um sistema, usualmente sob condições que requerem alocação de recursos escassos [2].

Uma dos métodos de Pesquisa Operacional é a Programação Linear (PL), que é uma técnica de otimização que aplica equações e inequações lineares para maximizar ou minimizar uma função objetivo linear respeitando restrições que também são equações lineares[3].

A resolução dos modelos de PL pode utilizar diversos métodos, como o método gráfico, algébrico , método de pontos inteiros, método simplex, entre outros. Independente do método utilizado, a resolução busca encontrar uma solução ótima para o problema [2][3].

O Solver é uma ferramenta solucionadora baseada em planilhas eletrônicas. Este tipo de solucionador se torna cada vez mais popular já que os formatos de planilha são familiares a maioria dos gestores. Mas existe uma limitação quanto ao número de variáveis ou restrições aplicáveis a estes softwares. Outros inúmeros aplicativos são usados para modelagem com uma capacidade de processar números maiores de variáveis, mas com uma linguagem de programação específica, o que dificulta sua utilização para a maioria das pessoas[4].

[3] afirma ainda que o Solver também pode resolver problemas de Programação Inteira (PI) ou Programação Inteira Binária (PIB), bastando para isso inserir suas respectivas restrições.

\section{METODOLOGIA}

Para este estudo empregou-se a abordagem qualitativa e quantitativa, tipo de pesquisa descritiva através de pesquisa de campo, pois a investigação ocorreu no local em que se observam as características desejadas, uma escola de formação profissional da cidade de Itabira, onde se aplica alocação de docentes por competências.

Compreende-se que o universo desta pesquisa se constituiu dos docentes e das disciplinas dos cursos das três áreas de atuação de uma escola profissionalizante da cidade de Itabira, Minas Gerais e a amostra se constituiu de quatorze docentes e das setenta disciplinas dos cursos da área de eletroeletrônica do turno da manha. O critério de amostragem utilizado foi o não probabilística por acessibilidade. Os sujeitos participantes desta pesquisa foram quatorze instrutores de formação profissional do referido setor tomado como amostra, dois supervisores técnicos diretamente envolvidos na atividade de alocação por competência e o gerente da unidade.

Como instrumento de coleta de dados, utilizou-se a coleta documental, observação participativa e a entrevista semi estruturada. A abordagem quantitativa deste trabalho foi tratada através de métodos da estatística descritiva e modelo matemático de PO utilizando a ferramenta MS-Excel. A técnica de análise de conteúdo foi utilizada para aspectos da abordagem qualitativa.

O estudo desta pesquisa foi desenvolvido em uma escola de formação profissional pertence ao Serviço Nacional de Aprendizagem Industrial (SENAI), é situada na cidade de Itabira e fornece cursos de aprendizagem, qualificação e técnicos de nível médio nas áreas de eletroeletrônica, metal-mecânica e construção civil. Possui oitenta e seis colaboradores diretos 
sendo cinquenta e dois instrutores de formação profissional que são alocados em disciplinas de vinte e sete cursos distintos.

A empresa pesquisada tem como um de seus processos administrativos a alocação dos instrutores em disciplinas baseada nas competências dos profissionais. Sendo que, a atividade de alocar estes docentes em disciplinas nas quais apresentem maior competência se torna mais complexa devido ao fato de algumas disciplinas possuírem apenas um ou dois instrutores mapeados sendo consideradas críticas para o processo que é realizado de forma manual pelos supervisores técnicos da unidade.

\section{ANALISE DE RESULTADOS}

Nesta etapa são apresentadas as implicações do modelo matemático utilizado para alocação de instrutores em uma escola de formação profissional da cidade de Itabira.

Foram realizadas coletas de dados e entrevistas em uma escola de formação profissionalizante da cidade de Itabira, que realiza alocação de docentes em disciplinas de acordo com suas competências específicas para cada disciplina. Os documentos analisados são planilhas eletrônicas. Estas contêm informações sobre a classificação das competências dos instrutores para cada disciplina e a alocação realizada nos últimos semestres. Os entrevistados são gestores desta empresa ligados ao processo de alocação de mão de obra. $\mathrm{Na}$ tabela a seguir estão os dados dos entrevistados.

TABELA 1

Dados dos entrevistados

\begin{tabular}{|c|c|c|c|c|c|}
\hline Entrevistado & Idade & Cargo & Escolaridade & Tempo no cargo & Tempo de empresa \\
\hline 1 & 26 anos & Supervisor técnico & Superior em andamento & 4 anos & 6,5 anos \\
\hline 2 & 41 anos & Gerente de Centro de Formação Profissional & Superior & 3,5 anos & 20 anos \\
\hline 3 & 40 anos & Supervisor técnico & Superior & 4 anos & 16 anos \\
\hline
\end{tabular}

Fonte: Elaborado pelo autor da pesquisa.

Desta forma, este capítulo esta organizado em quatro sub-tópicos: descrição do processo de alocação de instrutores por competências, o modelo de Programação Linear, comparação entre os resultados obtidos e a identificação de vantagens e desvantagens do modelo em relação ao processo manual.

\subsection{DesCrição do Processo de AlocaÇÃo de InSTRUTORES}

A alocação de instrutores em disciplinas ocorre em intervalos semestrais na escola observada. São considerados fatores como a disponibilidade de instrutores, as disciplinas que ocorrerão no semestre, a classificação das competências dos instrutores nas disciplinas e a ocorrência de projetos paralelos que demandem a designação de instrutores.

O processo de alocação, embora utilize um computador, pode ser considerado como um sistema manual, pois as operações são realizadas e as decisões tomadas por seres humanos. Este processo considera diversos dados que são processados de forma manual.

Segundo observação realizada in loco pelo pesquisador, o primeiro fator é a demanda dos cursos. Consideram-se quais cursos e módulos estão começando no semestre e quais as disciplinas devem ser ministradas nestes cursos/módulos. A partir destes dados pode-se quantificar o número de instrutores necessários para atender esta demanda.

Outro aspecto é a disponibilidade de instrutores. Verificam-se quantos e quais instrutores estão disponíveis para alocação já que alguns instrutores ficam incumbidos de outros projetos ou já estão alocados em disciplinas de módulos em andamento. 
A alocação e montagem dos horários consideram ainda as informações sobre a classificação de competências dos instrutores que definem o nível de competência de cada instrutor em cada uma das disciplinas. Esta classificação foi realizada com base em uma auto avaliação, na qual os instrutores definem numa escala de 0 a 3 , qual é o sua competência para lecionar cada disciplina dos cursos da instituição. A escala se traduz em 0 o instrutor não possui domínio sobre a disciplina, 1 possui domínio parcial sobre o conteúdo da disciplina, 2 possui competências, mas não gosta de lecionar a disciplina, 3 possui competências e gosta de ministrar a disciplina.

$\mathrm{O}$ fato de as disciplinas ocorrerem num modelo onde toda a carga horária de uma disciplina é ministrada antes que se inicie outro conteúdo na mesma turma, é um aspecto considerado. Devido a isto, um mesmo instrutor não pode ser alocado em disciplinas que ocorram simultaneamente, mesmo que em turmas diferentes. Isto porque já existe um horário pré-definido com as disciplinas já alocadas, nos respectivos horários e turmas. O que deve ser definido é qual instrutor lecionara cada disciplina.

A classificação das competências e a disposição dos instrutores nas disciplinas mais próximas de seu domínio caracterizam o sistema de gestão por competência, utilizado na escola. Neste processo são identificados e alocados os talentos das pessoas e as decisões a este respeito são tomadas manualmente pelos gestores sem o uso de um software que o auxilie nesta tarefa.

A observação e descrição deste processo são essenciais para a formulação do problema de programação linear, pois permite identificar os elementos que o compõem.

\subsection{Modelo de ProgramaÇão Linear}

De acordo com a descrição do processo de alocação desenvolvida a partir da observação realizada pelo pesquisador, pode-se definir como objetivo do problema a maximização do somatório das competências alocadas. Entende-se por competências alocadas o nível de competência que o instrutor designado para trabalhar esta disciplina apresentou em sua autoavaliação. Desta forma, foi definido como elementos do modelo, apresentados a seguir.

Variável de decisão:

$\mathrm{X}_{\mathrm{i}, \mathrm{d}}$ : assume 1 quando o instrutor i esta alocado na disciplina $\mathrm{d}$, caso contrario, assume 0 .

Parâmetros:

$\mathrm{C}_{\mathrm{i}, \mathrm{d}}$ : nível de competência, de 0 a 3 , do instrutor i na disciplina d.

$\mathrm{A}_{\mathrm{d}, \mathrm{j}}$ : assume 1 quando a disciplina d é coincidente (acontece no mesmo horário) com a j, 0 caso contrario

Conjuntos:

Inst: $\{1$ a 14$\}$; conjunto dos instrutores da amostra

Disp: $\{1$ a 70$\}$; conjunto das disciplinas da amostra

Dispcon: $\{$ Discp-d $\}$; conjunto das disciplinas da amostra menos a disciplina " $d$ ". 
Modelo:

$\operatorname{Max} \sum_{i \in \operatorname{mat}} \sum_{d \leq D i s p}\left(C_{i, d} X_{i, d}\right)$

Sujeito às restrições:

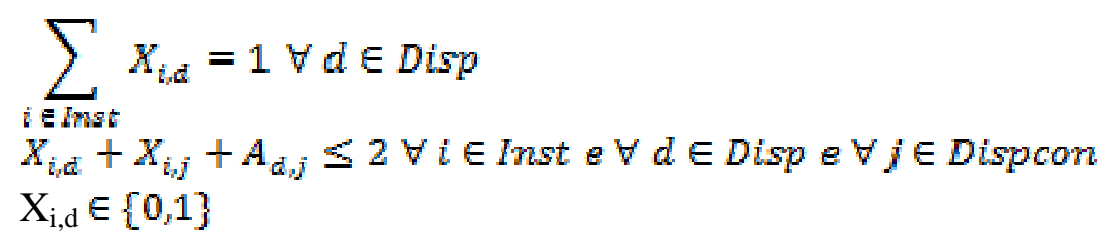

A função objetivo deste modelo relaciona à classificação das competências e esta classificação assume uma relação de melhoria quando maior o valor, então a função objetivo deve ser de maximização. Maximizar as competências alocadas para que mais instrutores sejam alocados em disciplinas para as quais possuam competências de níveis altos. Uma competência alocada é o valor da classificação de competência do instrutor que foi designado a ministrar uma disciplina.

A primeira restrição representa a condição de se ter um e apenas um instrutor alocado em cada disciplina, pois se a variável alocação $X_{\mathrm{i}, \mathrm{d}}$ só pode assumir os valores 0 ou 1 , para que o somatório das alocações por disciplina resulte em 1, apenas uma alocação deve possuir valor 1 e as demais necessariamente são 0 . Esta condição deve ser atendida para todas as disciplinas.

A segunda restrição, apresentada delimita o fato de um mesmo instrutor não poder ser atribuído a duas disciplinas que ocorrem simultâneas. Como esta modelagem parte da existência de um horário pronto que define os tempos de início, término e durações das disciplinas, é necessário apenas um parâmetro que indique se duas disciplinas são, ou não, coincidentes. Este indicador de coincidência é representado por " $\mathrm{A}$ " e quando se refere a duas disciplinas específicas é acompanhado de índices subscritos " $\mathrm{A}_{\mathrm{d}, \mathrm{j}}$ ”. É um parâmetro do tipo binário, onde o valor 0 indica que as disciplinas não são coincidentes, e o valor 1 indica que as disciplinas ocorrem de forma simultânea.

O modelo apresentado foi resolvido através pela ferramenta Solver do MS-Excel, com a seguinte configuração: tempo máximo de 100 segundos, 100 iterações, precisão de 0,000001, tolerância $5 \%$ e convergência de 0,0001 . Os resultados obtidos serão discutidos no tópico a seguir.

\subsection{COMPARAÇÃO dOS RESUltados OBTIDOS}

Este tópico pretende indicar as implicações de se utilizar um modelo de PL para alocar instrutores em disciplinas da escola profissionalizante estudada. Para tanto realiza-se uma comparação entre os dados obtidos através da observação e pesquisa documental sobre o processo manual realizado e os resultados obtidos por meio do modelo e dos documentos gerados a partir de sua resolução. Utiliza-se a estatística descritiva, que permite apresentar e analisar os dados obtidos.

Para determinar as implicações do modelo realizou-se um comparativo entre alguns indicadores de desempenho. Estes indicadores são o percentual de disciplinas que receberam instrutores com domínio 3, percentual alocado em domínio 2, em domínio 1 e o percentual de disciplinas com instrutores de domínio 0, ou seja, quantidade de disciplinas que receberam instrutores que não dominam seu conteúdo. Além destes, outro indicador que permite 
comparar o processo de alocação manual e o modelo de PL, é a diferença percentual entre as competências alocadas pelos dois métodos.

A alocação manual de instrutores permitiu que 9 das 70 disciplinas fossem ocupadas por instrutores que não dominam seu conteúdo. Isto representa 12,86\% das disciplinas. Com a utilização do modelo de PL este número cai para 2 disciplinas passando a representar 2,86\% do número total. Uma redução de $77,78 \%$ no número de disciplinas com competência de nível 0 alocada. Estes dados comparativos podem ser observados na figura 1.

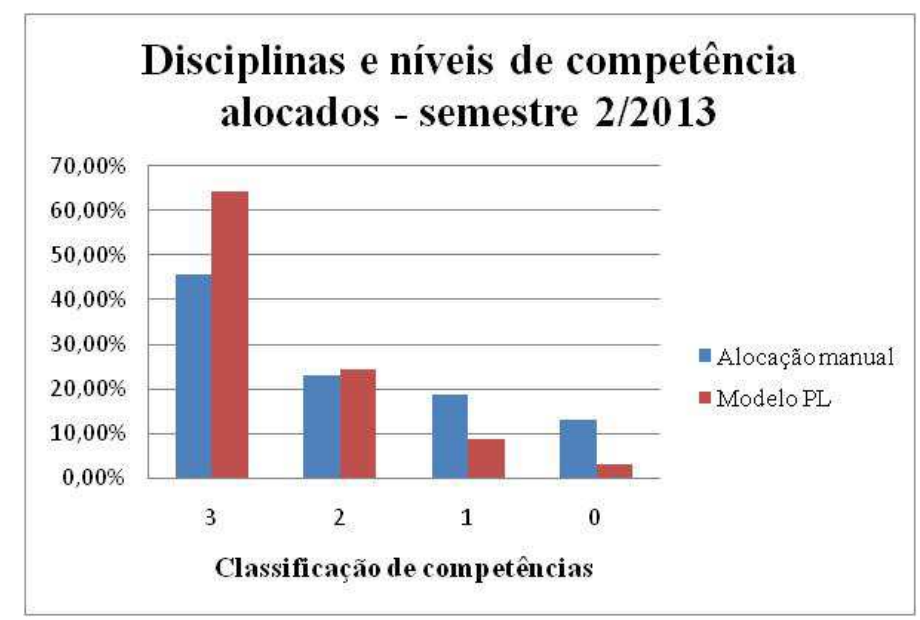

FIGURA 1: Disciplinas por nível de competência - Manual X modelo de PL Fonte: elaborado pelo autor da pesquisa.

Outro indicador desenvolvido é o somatório de competências alocadas. Que indica de forma geral a qualidade da alocação realizada no semestre. É definido por um valor adimensional que quanto maior, mais disciplinas foram alocadas com as melhores competências. O processo de alocação manual obteve um somatório de competências alocadas igual a 141. Com a utilização do modelo este valor aumenta para 175. Um aumento de $24,11 \%$ como pode ser observado na figura 2 .

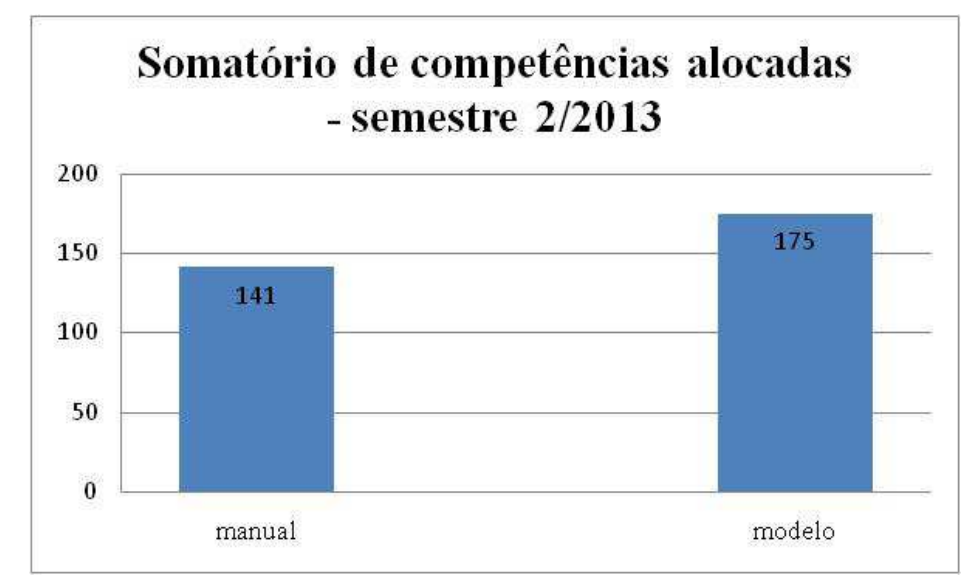

FIGURA 2: Somatório das competências alocadas no segundo semestre de 2013 Fonte: elaborado pelo autor da pesquisa.

Os dados apresentados na Tabela 2, resumem os índices que demonstram as implicações do modelo de PL sobre o método manual, em tarefas de alocação de instrutores em disciplinas com base em competências profissionais em uma escola de formação profissionalizante de Itabira. 
TABELA 2

\begin{tabular}{lcc}
\hline \multicolumn{3}{c}{ implicações processo manual X Modelo de PL } \\
\hline Disciplinas com instrutores de nivel 3 (\% da amostra) & Manual & Modelo de PL \\
\hline Disciplinas com instrutores de nivel 2 (\% da amostra) & 22,86 & 64,28 \\
\hline Disciplinas com instrutores de nivel 1 (\% da amostra) & 18,57 & 8,75 \\
\hline Disciplinas com instrutores de nivel 0 (\% da amostra) & 12,86 & 2,86 \\
\hline Somatório de Competências alocadas & 141 & 175 \\
\hline Tempo gasto para gerar a designação (dias) & 10 & 1 \\
\hline
\end{tabular}

Fonte: Elaborado pelo autor da pesquisa

Este comparativo apresenta as implicações de se usar um modelo de PL da pesquisa Operacional para alocação de instrutores em disciplinas de uma escola de formação profissional. As vantagens e desvantagens deste modelo foram questionadas aos gestores desta escola em entrevista realizadas no local de trabalho.

\subsection{Identificação de Vantagens e Desvantagens do Modelo em RelaÇão ao Processo Manual}

Neste tópico pretende-se identificar as vantagens e desvantagens do modelo de PL para alocação de instrutores, por meio da análise de conteúdo das entrevistas realizadas com os gestores da escola de formação profissional.

Quando questionados sobre o processo de alocação de instrutores realizado atualmente os entrevistados afirmaram que esta alocação é realizada com base nas competências e preferências dos profissionais.

O processo hoje, nos fazemos de forma que se busque alocar os instrutores de acordo com suas competências, semelhante ao seu projeto, mas fazemos tudo manualmente. Temos a planilha onde cada instrutor preencheu com sua respectiva afinidade com as disciplinas e quando as turmas acontecem aqui no SENAI agente busca mecanicamente alocar estes instrutores em disciplinas relacionadas à sua área de competência. (ENTREVISTADO 1)

Tem uma planilha, que ela tem alguns mecanismos pra detecção de sobre locação, mas os lançamentos de instrutores nas disciplinas ele é manual buscando sempre colocar o instrutor em disciplinas a qual dominam. (ENTREVISTADO 2).

No inicio agente utilizava muito aquela planilha que foi feita, para ver qual é a disciplina que cada instrutor tem facilidade para poder montar o horário o mais coerente com as competências dos instrutores o possível. (ENTREVISTADO 3).

Os entrevistados destacam o uso da planilha de classificação de competências, nomeada neste trabalho como documento 1, para alocar os instrutores de acordo com suas habilidades e domínio do conteúdo. Afirmam ainda que o processo de alocação é realizado de forma manual.

[1], afirma que competências humanas são a expressão dos conhecimentos, habilidades e atitudes no desempenho do trabalho para agregar valor à organização e às pessoas. 
A gestão por competências é um modelo de administração de pessoas baseada nos conhecimentos, habilidades e atitudes das pessoas. Deve-se avaliar as competências necessárias, mapear as competências dos profissionais, identificar a distância entre as competências necessárias e aquelas que a organização já possui. A certificação de competências é a fase na qual se avalia o domínio de competências pelas pessoas. Completando o ciclo deve-se, estabelecer práticas que minimizem a divergência entre as competências necessárias e as existentes. Uma destas práticas consiste na identificação e alocação de talentos, ou seja, fazer com que o colaborador exerça a atividade mais adequada à sua base de competência [1].

Com base nas afirmações dos entrevistados e nos conceitos teóricos apresentados pelos autores, pode-se afirmar que atualmente na escola de formação profissional utiliza-se da gestão por competências. No processo de alocação de docentes estão presentes as etapas de avaliação das competências necessárias e mapeamento das competências dos profissionais da instituição. A busca por uma alocação coerente com as habilidades dos profissionais caracteriza a tentativa de minimização da divergência entre as competências necessárias e as existentes.

Ao serem questionados sobre as vantagens do método manual, os gestores apresentaram aspectos como o controle sobre o processo e a flexibilidade na tomada de decisões.

a vantagem do manual é que o supervisor ele tem o conhecimento, ele sabe de tudo que está acontecendo, a visão de que o supervisor tem pois como foi ele quem fez, quem lançou se alguém precisar fazer uma troca terá a visão de onde está a possibilidade de troca. (ENTRVISTADO 2)

Este relato mostra a crença do gestor de que o processo manual é flexível, permitindo alterações e trocas entre instrutores e disciplinas. Outro aspecto levantado para esta questão é o fato de que os profissionais são qualificados para realização das tarefas quando não existe um instrutor competente disponível.

você precisa gerar uma qualificação. E esta situação é justamente a hora que você tem para conversar com este instrutor ver se ele tem a disposição de buscar e aprender aquele conteúdo e caso este processo ocorra, você consegue mais pessoas qualificadas para aquele conteúdo que antes era de escassa mão de obra qualificada para ele. Com isto o profissional tem um ganho e a escola tem um ganho com este funcionário. (ENTREVISTADO $1)$.

Os aspectos apresentados pelos entrevistados como vantagens do processo manual de alocação de instrutores dizem respeito à flexibilidade, ao controle que os supervisores apresentam do processo e à possibilidade de se aperfeiçoar as competências dos profissionais. [1], relaciona a educação corporativa como um dos métodos utilizados para fornecer competências a organização. Estas competências devem estar em consonância com os objetivos organizacionais.

Os processos manuais apresentam como vantagem a presença da educação corporativa como ferramenta para agregar competências aos instrutores e consequentemente à organização. Este é um valor apresentado nas entrevistas e evidenciado como ferramenta da gestão por competências pelo autor citado anteriormente.

As vantagens relacionadas pelos entrevistados para a realização de suas atividades de alocação e as demais tarefas da supervisão, foram a otimização do tempo e a disponibilidade dos supervisores para atender às demais demandas do cargo. 
Com a otimização do tempo gasto para realizar a alocação dos instrutores, os supervisores técnicos ficariam disponíveis para realizar as demais tarefas a que o cargo se submete como atendimento aos instrutores e melhorias nos ambientes de aulas práticas. Os entrevistados destacam ainda, que esta seria uma melhor utilização do trabalho dos gestores, desta forma suas competências também seriam otimizadas, além de evitar o retrabalho.

Para garantir o sucesso do futuro as empresas precisam potencializar seu capital humano hoje. Para isto é necessário algumas medidas como a identificar o capital humano por meio de um banco de talentos com o mapeamento das competências de cada funcionário, potencializar as competências de seus funcionários aprimorando o sistema de identificação e alocação de talentos. [1]

Esta disponibilidade pode ser entendida como uma alocação de competências dos supervisores em maior conformidade com os objetivos estratégicos da organização. $\mathrm{O}$ que aumenta a abrangência do modelo para além de suas fronteiras. Destaca-se então como vantagens para os supervisores a redução no tempo gasto para realizar a alocação de instrutores, além da maior conformidade de suas atividades com suas habilidades e conhecimentos, ou seja, suas competências profissionais.

Quando os entrevistados foram questionados a respeito das vantagens do modelo de PL para os profissionais alocados os principais aspectos abordados foram maior coerência entre o conteúdo das disciplinas ministradas com seus conhecimentos e habilidades, menor carga de trabalho no planejamento e preparo das aulas.

se se aloca um instrutor numa disciplina que possua mais domínio a tendência é que ele consiga passar aquilo dali de uma melhor forma, com uma didática melhor, porque ele tem pleno, ele tem consciência que ele tem domínio daquilo. Provavelmente material de pesquisa, outras fontes que agente consiga obter este conhecimento já está no domínio deste instrutor também. São inúmeras facilidades que seriam o sonho de todo instrutor, dar aula apenas daquilo que ele domina plenamente. (ENTREVISTADO 1).

o que eu vejo como vantagem e que ele vai ter sua competência otimizada e alem disso vai ter o supervisor mais tempo disponível para atende-lo e para dar suporte na sua atividade fim que é dar aula. (ENTREVISTADO 2).

Pelo sistema você vai cercar isso mais, na hora que estiver montando lá dificilmente você vai colocar um instrutor que não gosta de passar uma matéria, que não tem domínio daquela matéria pra ministrar o conteúdo. (ENTREVISTADO 2).

O conteúdo das respostas demonstra que na percepção dos gestores as vantagens do modelo de PL para os instrutores alocados estão no fato destes instrutores terem suas competências potencializadas, melhorando a qualidade de suas aulas. Também apresentaram a melhor utilização do tempo dos instrutores, e o aumento da satisfação destes profissionais com o trabalho.

As competências traduzem o potencial do conhecimento, habilidades e atitudes. Estão relacionadas à forma como as pessoas realizam as atividades com mais empenho e criatividade. Estas competências são adquiridas não só pela formação teórica, mas pelas experiências adquiridas em situações anteriores [5].

Confrontando a teoria com as afirmações dos entrevistados, pode-se afirmar que o instrutor alocado em sua área de competência apresenta os conhecimentos, habilidades e atitudes necessárias para desempenhar sua função com mais empenho e criatividade. Outro aspecto esta relacionado à satisfação do profissional com o trabalho, o que fica evidente 
quando mencionado pelo Entrevistado 1 em "são inúmeras facilidades que seriam o sonho de todo instrutor, dar aula apenas daquilo que ele domina plenamente".

Também foram apontadas desvantagens no processo de alocação de instrutores por meio do modelo de PL por um dos entrevistados.

eu acho que é muito importante buscar um meio termo, na medida do possível alocar as pessoas nas suas habilidades, para que elas não passem aperto, trabalhem com mais domínio, que os alunos consigam ser mais beneficiados, só que por outro lado eu tenho que dar a oportunidade da pessoa se desenvolver, trabalhar várias disciplinas faz com que o instrutor se qualifique (ENTREVISTADO 1).

O entrevistado considera aspectos como a pouca flexibilidade e a menor possibilidade geração de conhecimento para o instrutor como desvantagens. Isto evidencia que o gestor acredita que o modelo tornará o processo mais rígido, mantendo os instrutores em poucas ou na mesa disciplina.

Competência está ligada a atitude do indivíduo perante as situações profissionais. Estas atitudes consideram sua capacidade de tomar iniciativa, assumir responsabilidades e utilizar uma inteligência prática, ou seja, conhecimentos adquiridos e transformados pela diversidade destas situações [6].

Relacionando a visão do entrevistado e a teoria, podemos perceber que a afirmação do gestor quanto ao desenvolvimento das competências esta coerente com o autor. Desta forma quanto menor a variedade das experiências vividas pelo instrutor menor será sua formação de competências.

Para os gestores, a alocação de instrutores através de um modelo de PL, implica ao processo de alocação maior agilidade e otimização do tempo dos gestores, maior disponibilidade dos gestores para outras de suas atividades, e ganhos de qualidade no resultado da designação de profissionais. Contudo, o processo fica mais estático e automático, saindo do controle total para um controle parcial por parte dos gestores. Para os profissionais alocados as vantagens apontadas é a melhoria da qualidade dos serviços prestados e otimização do tempo gasto com planejamento de aulas, mas confere uma maior especialização, o que pode reduzir o desenvolvimento de competências em áreas distintas.

\section{CONCLUSÕES}

Através da pesquisa documental e observação foi possível desenvolver e descrever um modelo que atendesse as condições reais do ambiente analisado. Foram isolados os objetivos, parâmetros e as restrições aplicáveis ao modelo. Este modelo atingiu uma solução factível e otimizada para a alocação dos instrutores em suas respectivas disciplinas de domínio. Desta forma, pode-se afirmar que este trabalho alcançou seu objetivo de desenvolver e descrever um modelo de PL para esta finalidade.

Percebeu-se como implicações do modelo de PL o aumento nos índices de instrutores alocados em disciplinas para as quais possuem máxima competência. Além da redução de instrutores alocados em disciplinas das quais não possuíam domínio. O número de instrutores designados para disciplinas para as quais possuíam domínio intermediário sofreu pouca alteração.

Constatou-se as vantagens e desvantagens do modelo de PL em relação ao método manual. Os gestores consideram o modelo como uma ferramenta útil para o processo de alocação de docentes. Estes apontaram como principais vantagens a melhoria da qualidade das aulas dos instrutores, a redução dos tempos gastos com planejamento de aulas e com a elaboração do horário semestral, e a maior disponibilidade de tempo para acompanharem as 
aulas práticas e se dedicarem as demais atividades de gestão. Apontaram como desvantagem do modelo de PL o aspecto de que a alocação manual é mais flexível, possibilitando mudanças quando necessário.

A modelagem por meio da Pesquisa Operacional para alocar profissionais com base em suas competências pode ser utilizada não apenas nesta ou outras escolas de formação profissional, mas também em outros ramos de atividade. Um processo anterior a alocação de profissionais por competências é a avaliação das competências presentes e necessárias. Desta forma, sugere-se pesquisas futuras que analisem a forma como as empresas avaliam estas competências e identifiquem organizações passiveis de empregar a metodologia utilizada neste trabalho em áreas distintas, com o objetivo de avaliar as implicações dos modelos de PO para alocação por competências de forma generalizada.

\section{REFERÊNCIAS BIBLIOGRÁFICAS}

[1]CARBONE, Pedro Paulo et al. Gestão por competências: gestão do conhecimento. Rio de Janeiro: Editora FGV, 2005.

[2]ARENALES, Marcos et al. Pesquisa operacional: para cursos de engenharia. Rio de Janeiro: Elsevier, 2007

[3]PASSOS, Eduardo José Pereira Franco dos. Programação linear como instrumento da pesquisa operacional. São Paulo: Atlas, 2008.

[4]HILLIER, Frederick S.; LIEBERMAN, Gerald J. Introdução à pesquisa operacional. Tradução de Ariovaldo Griesi. São Paulo: McGraw-Hill, 2006.

[5]SERVIÇO NACIONAL DE APRENDIZAGEM INDUSTRIAL - DEPARTAMENTO NACIONAL. Certificação de competências. Brasília: SENAI/DN, 2008.

[6]ZARIFIAN, Philippe. O modelo da competência: trajetória histórica, desafios atuais e propostas. Tradução de Erick Roland René Heneault. São Paulo: Editora Senac São Paulo, 2003. 